\title{
O CONTEXTO LOCAL COMO ELO ENTRE CIÊNCIAS DA NATUREZA E EDUCAÇÃO DO CAMPO
}

\author{
FONSECA, Eril Medeiros $\mathrm{da}^{{ }^{*}}$; BIERHALZ, Crisna Daniela Krause ${ }^{1^{* *}}$ \\ ${ }^{1}$ Universidade Federal do Pampa \\ erilmf@gmail.com* \\ crisnakrause@gmail.com**
}

\section{RESUMO}

Apresenta-se um recorte da pesquisa desenvolvida na Universidade Federal do Pampa - Campus Dom Pedrito, no curso de Licenciatura em Ciências da Natureza. Objetivou-se sugerir articulações entre Ciências e o contexto sócio-político-econômico e cultural do campo. Analisaram-se os cadernos de Ciências dos anos finais do Ensino Fundamental de uma escola do campo do Rio Grande do Sul. É uma pesquisa qualitativa, explicativa e documental, aliando três concepções teóricas: Educação do Campo,
Ensino de Ciências e formas de articulação com o meio. Constatou-se que os conteúdos de Ciências são trabalhados de forma mecânica, seguindo a sequência do livro didático. Não se evidenciou imbricamento entre conteúdos de Ciências e contexto local. Estima-se que as propostas temáticas: terrário e alimentação são potencializadoras da construção do conhecimento, integrando os conteúdos de Ciências e contexto cultural dos sujeitos do campo.

PALAVRAS-CHAVE: Ensino de Ciências. Educação do campo. Contexto local.

\section{THE LOCAL CONTEXT AS A BOND BETWEEN NATURAL SCIENCES AND FIELD EDUCATION}

\section{ABSTRACT}

We present a research cut developed at the Federal University of Pampa - Campus Dom Pedrito, in the degree course in Natural Sciences. The objective was to suggest articulations between Sciences and the socio-politicaleconomic and cultural context of the field. We analyzed the science notebooks of the final years of Elementary School in a school in the Rio Grande do Sul field. It is a qualitative, explanatory and documentary research combining three theoretical concepts: Field Education,
Science Teaching and forms of articulation with the middle. It was verified that the contents of Sciences are worked mechanically, following the sequence of the didactic book. There was no overlap between contents of science and local context. It is estimated that the thematic proposals: terrarium and feeding are potentials of the construction of the knowledge, integrating the contents of Sciences and cultural context of the subjects of the field.

KEYWORDS: Science education. Rural education. Context.

\section{EL CONTEXTO COMO ENLACE LOCAL ENTRE CIENCIAS DE LA NATURALEZA Y LA EDUCACIÓN RURAL}

\section{RESUMEN}

Se presenta un estudio desarrollado en la Universidad Federal de Pampa - Campus Dom Pedrito, el Grado en Ciencias Naturales. El objetivo era sugerir vínculos entre la ciencia y el contexto socio-político-económica y cultural del campo. Analizados los libros de ciencia de los últimos años de la escuela primaria a la escuela de Rio Grande do Sul campo es una investigación cualitativa, explicativo y documental, la combinación de tres concepciones teóricas: la educación rural, la educación científica y las formas de cooperación con el medio. Se encontró que el contenido de la ciencia se trabajó mecánicamente, siguiendo la secuencia de libro de texto. No se presentó entrelazamiento de contenido científico y el contexto local. Se estima que los temas propuestos: terrario y los alimentos están potenciando la construcción del conocimiento, integrando los contenidos de la ciencia y el contexto cultural del campo.

PALABRAS CLAVE: Enseñanza de Ciencias. Educación rural. Contexto local. 


\section{INTRODUÇÃO}

Quando se pensa um planejamento para qualquer nível e/ou modalidade de ensino é relevante conhecer e contemplar os saberes dos sujeitos e a cultura da região. Na Educação do Campo isso significa vincular a educação aos espaços de trabalho, onde as pessoas constroem e reproduzem a sua própria existência (FERNANDES, 2012). Neste sentido, o Ensino de Ciências permite articular os saberes "construídos a partir de experiências, das relações sociais, das tradições históricas e principalmente, das visões de mundo" (MOLINA, 2006, p. 12).

A Educação do Campo, em sua práxis, discute o significado das questões referentes ao trabalho, terra e valorização dos conhecimentos dos trabalhadores rurais (KOLLING; CERIOLI; CALDART, 2002) e relaciona-se à concepção teórica de alfabetização científica, que consiste na organização de conhecimentos necessários a compreensão da sociedade e suas interdependências (CHASSOT, 2011). A alfabetização científica, ao mesmo tempo em que permite uma interpretação do mundo, sensibiliza para o entendimento de uma sociedade que valoriza "as reais necessidades da maioria da população brasileira e não limitada a acumular conhecimentos e avançar sem importar em que direção" (NASCIMENTO; FERNANDES; MENDONÇA, 2010, p. 227). Com isso, a apropriação de conhecimentos científicos deve atuar na "compreensão de conceitos que auxiliem no entendimento da conjuntura da realidade local, desencadeando assim um processo que contemple o desenvolvimento de consciência crítica" (FONSECA; BIERHALZ, 2016, p. 261).

Articular o Ensino de Ciências com as questões locais, regionais e as experiências que norteiam a vida dos indivíduos do campo é considerar que a Educação do Campo ocorre imbricada pelo contexto, pelos sujeitos, pelas histórias de vida e de luta.

A importância de vincular os saberes populares, as vivências dos sujeitos e o contexto local no processo de ensino e aprendizagem ancoram-se também nas orientações legais - Lei de Diretrizes e Bases da Educação Nacional (LDB) e Diretrizes Operacionais para a Educação Básica nas Escolas do Campo, pois ressaltam que a prática pedagógica deve estabelecer relação entre o estudado e o vivido, e correlacionar a cultura ao significado da terra (BRASIL, 1996), uma vez que no processo educativo todos os indivíduos são igualmente importantes e únicos, possuindo 
valores éticos, morais, políticos e humanos, com saberes e fazeres relevantes de serem socializados e problematizados no âmbito escolar (SILVA; MENEZES; REIS, 2012).

A vigente LDB, em seu artigo 28 , ressalta que os sistemas de ensino devem promover as adaptações necessárias à vida rural e às peculiaridades de cada região, perpassando pela organização dos conteúdos curriculares e metodologias, e ainda possibilitando ajustes no calendário escolar para as fases do ciclo agrícola e as condições do clima. Da mesma forma, os Parâmetros Curriculares Nacionais (PCN): Ciências Naturais (BRASIL, 1998) abordam em seu conteúdo questões relacionadas à realidade local, considerando temas que podem ser trabalhados por meio de observações, investigações ou pesquisa, para ampliar a compreensão do contexto que permeia o processo de aprendizagem, explorando o contexto através da análise de problemas ligados à realidade local e regional, realizando as relações entre vida e meio (FONSECA; BIERHALZ, 2016).

Desta forma, apresenta-se neste artigo um recorte da pesquisa qualitativa, explicativa e documental desenvolvida no curso de Licenciatura em Ciências da Natureza da Universidade Federal do Pampa (Unipampa) - Campus Dom Pedrito, intitulada Articulações entre o Ensino de Ciências e a Educação do Campo no município de Dom Pedrito-RS. Este recorte objetiva apresentar e discutir duas possibilidades de articulação entre o contexto do campo, a realidade e a cultura local com o processo de ensino e aprendizagem de Ciências.

\section{CONTEXTO DA PESQUISA}

A pesquisa pondera as articulações entre o contexto do campo e o Ensino de Ciências, considerando a região sudoeste do Rio Grande do Sul chamada de Campanha Gaúcha, caracterizada pelo Bioma Pampa. Dessa forma, torna-se importante apresentar o contexto que permeia este trabalho: a Universidade, o Município e a Escola do Campo.

A Universidade Federal do Pampa (Unipampa) é organizada em uma estrutura multicampi: dez campi, sendo um deles no município de Dom Pedrito, no qual funcionam cinco cursos de graduação: Zootecnia, Agronegócio, Enologia, e duas Licenciaturas: Educação do Campo e Ciências da Natureza. Os projetos pedagógicos dos cursos de Licenciatura apresentam 
caráter interdisciplinar e os licenciandos estão aptos para exercer a docência nos anos finais do Ensino Fundamental e no Ensino Médio, justificando a temática da pesquisa.

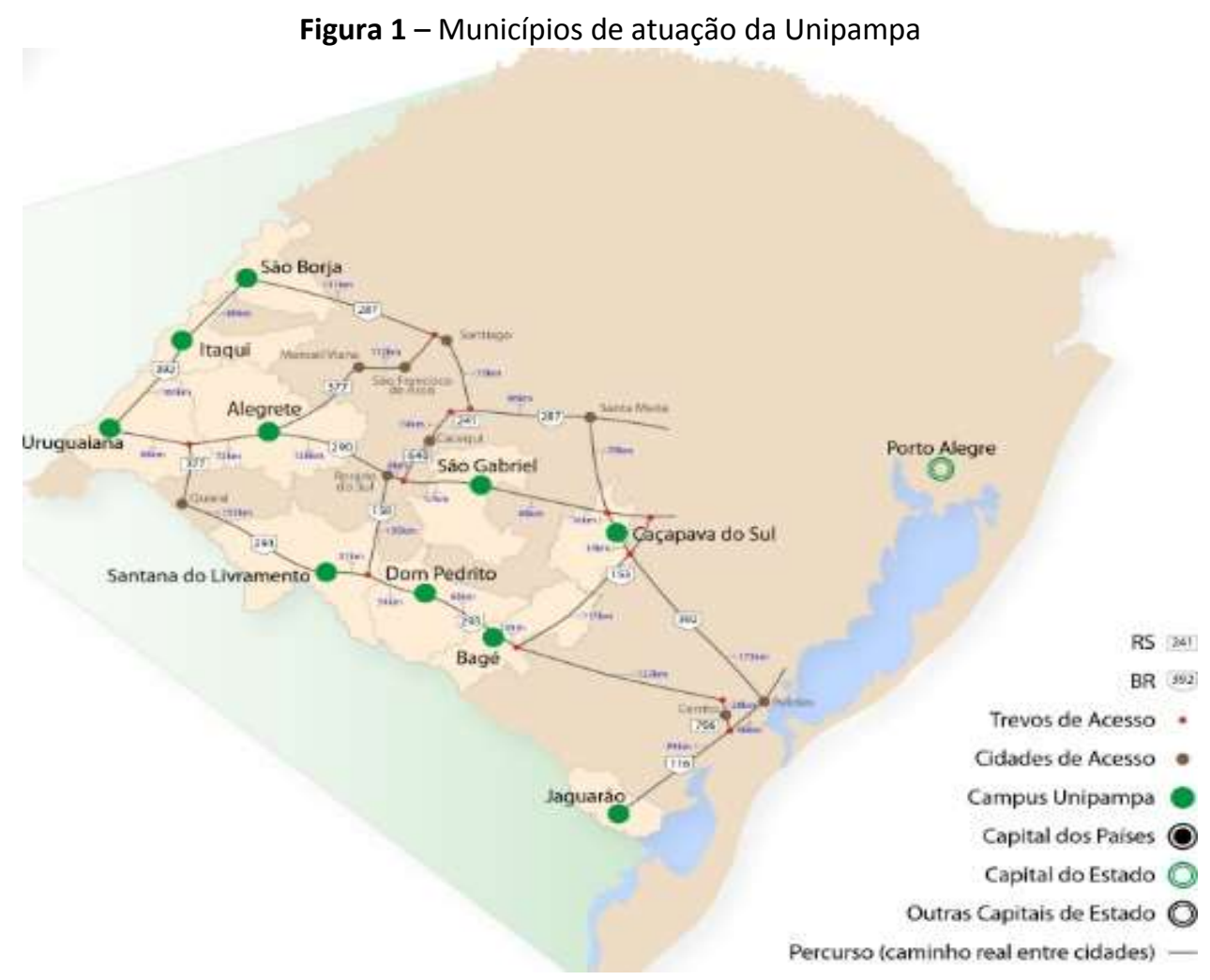

Fonte: Portal eletrônico da Unipampa.

De acordo com o IBGE ${ }^{1}$ (2016), o município de Dom Pedrito caracteriza-se como o quarto município em extensão do Estado do Rio Grande do Sul, com aproximadamente $5.200 \mathrm{~km}^{2}$, economia baseada na agricultura e pecuária extensiva, população de 39.853 habitantes e com densidade demográfica de 7,49 hab $/ \mathrm{km}^{2}$. Estima-se que $91 \%$ da população reside na área urbana e apenas $9 \%$ na área rural. Em contrapartida, vinte e uma escolas da rede de ensino, do total de cinquenta e sete, localizam-se em áreas rurais, justificando a urgência de estudos por parte da Universidade com esta modalidade de ensino.

A escola lócus da pesquisa é mantida pela Secretaria Municipal de Educação e Cultura, caracteriza-se como nucleada ${ }^{2}$, possui dezesseis professores devidamente habilitados em todas as áreas desde a Educação Infantil até o 9o ano do Ensino Fundamental. A instituição sofre com a

1 Disponível em: <http://www.cidades.ibge.gov.br/v3/cidades/municipio/4306601>.

2 A nucleação constitui-se em uma política pública de municipalização que consiste no fechamento de escolas do campo com poucos alunos matriculados, nas quais o ensino é multisseriado e na redistribuição dos alunos para escolas polo/núcleo, cujo deslocamento é realizado por transporte escolar.

Educação \& Formação, Fortaleza, v. 3, n. 7, p. 66-84, jan./abr. 2018

DOI: http://dx.doi.org/

http://seer.uece.br/redufor 
interferência das chuvas em seu calendário letivo; as condições de trafegabilidade das estradas inviabilizam a chegada de professores e alunos e interrompem a continuidade das aulas.

Os discentes são filhos de produtores rurais e assentados de reforma agrária, moradores de localidades próximas e que possuem elos de pertencimento com a região e com a escola, bem como filhos de funcionários de empresas de lavoura e pecuária, que trabalham por sazonalidade, por isso mudam-se em cada safra, residindo no campo em determinadas épocas. Fato interessante relaciona-se ao número expressivo de alunos que utilizam o transporte escolar do centro da cidade para a escola, pois em determinadas épocas do ano residem na zona urbana.

\section{METODOLOGIA}

A pesquisa caracteriza-se metodologicamente como uma pesquisa qualitativa, definida por Moreira (2011, p. 76) como "uma interpretação dos significados atribuídos pelos sujeitos à suas ações em uma realidade socialmente construída, através de observação participativa, isto é, o pesquisador fica imerso no fenômeno de interesse". Do ponto de vista do objetivo caracteriza-se como explicativa e em relação aos seus procedimentos técnicos assume caráter documental.

A análise de conteúdo, ancorada nas concepções de Bardin (2009), consiste em três etapas: pré-análise, exploração do material ou codificação e tratamento dos resultados obtidos/ interpretação. Na pré-análise, foram coletados os objetos que nortearam a pesquisa: cadernos de Ciências dos alunos dos anos finais do Ensino Fundamental. Segundo Fonseca e Bierhalz (2016), o trato com cadernos escolares ganha sentido quando se percebe que o mesmo retrata não apenas os conteúdos, mas a forma como são desenvolvidos, bem como a rotina da sala e a metodologia utilizada pelo professor, tornando-se um instrumento interessante para investigação, pois:

[...] são objetos que acompanham a escolarização, fazendo-se tão presentes nessa etapa, que acabam por tornarem-se inseparáveis das ideias de escola e ensino. A importância do caderno torna-se evidente não só pela sua constância nas escolas, mas também pelas funções que ocupa, já que é utilizado para registrar, resolver e corrigir a maioria das tarefas escolares. (SANTOS, 2002, p. 2-3).

Os registros das aulas de Ciências, realizadas através dos cadernos revelam, em grande parte, o trabalho desenvolvido pelo professor, a sua forma de conduzir a aula, os conteúdos que

Educação \& Formação, Fortaleza, v. 3, n. 7, p. 66-84, jan./abr. 2018

DOI: http://dx.doi.org/

http://seer.uece.br/redufor 
considera mais relevantes, os tipos de atividades feitas, bem como a maneira como observa a aprendizagem do aluno (FONSECA; BIERHALZ, 2016).

A segunda etapa, exploração do material, codificação de Bardin (2009), consistiu na transformação dos dados em unidades de registros, codificando as informações ou instrumentos a serem analisados. Dentre os doze cadernos recolhidos, elencou-se um de cada ano para a referida análise. Os cadernos são denominados respectivamente de: C6 - caderno do 6 ano, C7 - caderno do 70 ano.

Os critérios utilizados foram: conteúdo de Ciências e sua forma de apresentação (definições, explicações e exemplos); maneira de registro, como sendo cópia da matéria (folha/livro), relações feitas entre o conteúdo e o contexto local e sugestões de articulações entre ambos.

Segundo Siqueira e Araújo-Jorge (2008, p. 68), os cadernos são "documentos-fonte para a investigação no Ensino de Ciências", que não revelam todas as práticas e conteúdos estudados, porém podem indicar o cotidiano da sala de aula, revelando características relevantes do Ensino de Ciências (FONSECA; BIERHALZ, 2016).

Na terceira etapa, tratamento dos resultados obtidos e interpretação (BARDIN, 2009), ocorre a análise dos resultados brutos, de onde são extraídas as informações mais relevantes, apresentadas neste estudo.

\section{CONCEPÇÕES TEÓRICAS DO ENSINO DE CIÊNCIAS E EDUCAÇÃO DO CAMPO}

Por definição, Ciência é, segundo Fonseca (2002, p. 11), “[...] o saber produzido através do raciocínio lógico associado à experimentação prática. Caracteriza-se por um conjunto de modelos de observação, identificação, descrição, investigação experimental e explanação teórica de fenômenos". Considera-se, portanto, que a Ciência é mais uma das formas de compreender o mundo e as transformações que nele ocorrem, gerando conhecimentos que tornem os sujeitos aptos a interagir com tais transformações, intervindo em sua realidade.

Diante dessa concepção, percebe-se que é necessário um ambiente que oferte instrumentos favoráveis à construção do saber científico, aliado à compreensão de conceitos presentes no cotidiano. Por isso, o Ensino de Ciências deve desenvolver um conhecimento que vá 
além de conceitos e ideias, da cultura científica, para que os estudantes percebam os fenômenos da natureza e com isso estejam aptos a elaborar hipóteses, concepções e organizar ideias, preparando-os para agirem fora do ambiente escolar (CARVALHO, 2011).

O Ensino de Ciências é definido segundo Chassot (2011) como uma linguagem para facilitar a leitura do mundo e também relacionada com o conceito de alfabetização científica (CHASSOT, 2011, p. 62): "conjunto de conhecimentos que facilitariam aos homens e mulheres fazerem uma leitura do mundo em que vivem o que amplia o direito a escolha". Esta leitura possibilita uma apropriação de conceitos científicos, ampliando a dimensão de conhecimentos essenciais para a formação de uma postura em relação ao ambiente em que se vive. Considerar o Ensino de Ciências permeado pela "discussão das questões locais, da cultura regional e dos aspectos pertinentes às vivências dos sujeitos pertencentes ao campo significa reconhecer que o Ensino e a Educação do Campo ocorrem por meio de seu contexto" (FONSECA; BIERHALZ, 2016, p. 261).

As Diretrizes Operacionais para a Educação Básica nas Escolas do Campo caracterizam-se como uma conquista dos direitos dos povos do campo a terem e pertencerem ao lugar que lhes são de direito e terem neste espaço a oportunidade de uma educação digna e coerente com a sua realidade. Têm como base os saberes próprios dos estudantes relacionados à temporalidade e também a "memória coletiva que sinaliza futuros, na rede de ciência e tecnologia disponível na sociedade e nos movimentos sociais em defesa de projetos que associam as soluções exigidas por essas questões à qualidade social da vida coletiva no país" (BRASIL, 2002, p. 1). A efetivação destes aspectos atribui-se ao poder público no intuito de garantir a todas as populações do campo o acesso à educação.

É importante destacar que Educação Rural e Educação do Campo são concepções díspares, que não possuem as mesmas finalidades. A Educação Rural pode ser definida como a que se "apresenta dentro dos interesses capitalistas e do agronegócio, em que vê o campo/território apenas como um espaço de exploração e lucro, através da monocultura" (OLIVEIRA, 2013, p. 50). Percebe-se nesta concepção a visão exploratória dos territórios e, por consequência, das pessoas. A Educação Rural pode ser tratada como um espaço vinculado da vida, porém questiona-se em que condições articula a formação humana emancipatória e os projetos sociais. 
Os povos destas localidades são considerados como uma população "atrasada", na qual se tenta imprimir uma concepção de inferioridade para justificar os baixos investimentos, inclusive em Educação, a exemplo de escolas precárias, baixa qualidade das estradas e desvalorização dos professores e sua formação. Realidade na qual, infelizmente, o município de Dom Pedrito enquadra-se.

Tendo em vista a visão dicotômica entre campo e cidade (bom/ruim, moderno/atrasado, inferior/superior) e a relação de subordinação do rural ao urbano, afirma-se que esta Educação é sustentada pela expansão do agronegócio, sobrepondo os interesses dos latifundiários à dos pequenos produtores assentados de reforma agrária e agricultores familiares, na oferta de uma escolarização aos povos do campo. Não obstante, salienta-se que o sistema militar brasileiro também favoreceu os latifundiários no processo de exclusão do direito à educação das classes trabalhadoras do campo, já que muitos conflitos envolvendo os mesmos ocorreram na época do Regime Militar (PRIEBBERNOW, 2015).

Entre 1950 e 1960 intensificaram-se os movimentos ligados a uma Educação Popular, como Movimentos de Cultura Popular, Movimento de Educação de Base, Centros Populares de Cultura, entre outros. Porém, em 1980, o Movimento dos Trabalhadores Sem-Terra (MST) ganhou força, tendo como principal objetivo a Educação, emergindo políticas públicas voltadas para a Educação do Campo. Tal movimento ancora-se na concepção de Educação Libertadora de Paulo Freire, entendida na época como uma forma de libertação, contrária ao conceito de Educação Bancária.

A criação de escolas no meio rural no Brasil ganha força a partir do século XIX, surgindo como uma demanda social, quando o poder público insere uma visão pedagógica a estas escolas, visto que muitos operários reivindicavam a existência de escolas operárias e bibliotecas populares com o intuito de vincular a Educação com atividades de luta pela terra.

Portanto, a "nomenclatura Educação Rural foi reformulada e surge a denominação Educação do Campo, que passa a ser compreendida a partir de uma concepção de produção da vida em diferentes esferas, sendo estas culturais, econômicas, políticas e sociais" (ENISWELER; KLIEMANN; STRIEDER, 2015, p. 3). Surge uma nova concepção em relação ao processo educativo das populações do campo, compreendendo a Educação do Campo como aquela "voltada aos interesses e ao desenvolvimento sociocultural e econômico dos povos que ali habitam e 
trabalham, e que atende, às suas diferenças históricas e culturais, com seu modo de vida, de organização do trabalho e do espaço geográfico" (LUCAS, 2008, p. 119).

A partir destas concepções considera-se uma nova perspectiva de olhar para os povos do campo, ligada aos interesses da sua classe trabalhadora, que prima por seus valores instaurados e preserva o significado de sua própria cultura. Manifesta-se o anseio em consagrar escolas que possuam um Projeto Político-Pedagógico (PPP) vinculado às causas, interesses e história de seus indivíduos, estruturado através de um projeto popular (FERNANDES; CERIOLI; CALDART, 2011).

Fernandes (2006, p. 28) afirma que a Educação do Campo "[...] nasceu das demandas dos movimentos camponeses na construção de uma política educacional para os assentamentos de reforma agrária". Este aspecto justifica o fato de pensar a escola do campo a partir do vivido, considerando suas origens, pois construir uma escola do campo significa: "estudar para viver no campo [...] pensar a escola desde o lugar e os seus sujeitos; combinar com trabalho, com cultura. [...] A escola do campo tem que ser um lugar onde as crianças e os jovens possam sentir orgulho" (MEDEIROS; ROBL, 2013, p. 177).

É a partir desta origem que estes jovens têm o direito de definir sua própria trajetória, seu caminho enquanto sujeitos pertencentes ao campo, configurando uma ação emancipatória. Portanto, considera-se no presente trabalho que, pensar uma Educação do Campo voltada para o campo pressupõe rediscutir os objetivos do Ensino de Ciências principalmente com relação ao campo e vincular o processo de ensino e aprendizagem à realidade vivenciada.

\section{ARTICULAÇÕES ENTRE O CONTEXTO DO CAMPO E O ENSINO DE CIÊNCIAS}

No entendimento de que a pesquisa analisou a fragilidade de articulações entre os conteúdos de Ciências com a realidade do campo ou aspectos vinculados a tal, torna-se importante apresentar algumas possibilidades, não para que sejam utilizadas como receitas, mas para que possam servir de apoio aos professores na elaboração de suas próprias estratégias, pois compreendemos que cada realidade é única e deve ser valorizada.

Dessa forma utilizaram-se como base de organização alguns eixos temáticos apresentados pelos PCN, Ciências Naturais, quais sejam: "Vida e Ambiente" e "Ser Humano e 
Saúde" (BRASIL, 1998). A partir destes eixos emergiram algumas temáticas que nortearam as propostas para cada caderno, a saber: Terrário (C6) e Alimentação (C7).

Ressalta-se que as sugestões apresentadas são pensadas a partir da realidade da escola, da região e dos conteúdos identificados nos cadernos, considerando que o planejamento e sistematização de tais ideias dão-se de maneira colaborativa com a comunidade escolar, feito que se pretende articular em trabalhos futuros.

\section{CONTEÚDOS DO 60 ANO E A EXPERIÊNCIA COM O TERRÁRIO}

$\mathrm{Na}$ tabela 1, tabulação relacionada ao caderno do 60 ano, percebe-se que foram explorados os conteúdos Planeta Terra, Ecologia, Ar, Solo, Água e Sistema Solar respectivamente. Apresenta-se o terrário como uma das possibilidades de articulação, onde se pode construir um plano de estudo explorando os conceitos de solo, água, ar e questões ligadas à Ecologia.

Tabela 1 - Conteúdos e estrutura do caderno C6 do ano de 2015

\begin{tabular}{llll} 
Mês & \multicolumn{1}{c}{ Dia } & \multicolumn{1}{c}{ Conteúdo } & \multicolumn{1}{c}{ Características } \\
\hline \multirow{2}{*}{ Mar. } & $12 \mid 20$ & Ecologia & Definição; Exemplos; Exercício (citar, pintar) \\
\cline { 2 - 4 } & $13 \mid 16$ & Planeta Terra & Definição; Exercício (responder) \\
\hline \multirow{2}{*}{ Abr. } & 02 & Ecologia & Definição; Exemplos \\
\cline { 2 - 4 } & $16 \mid 27$ & Cadeia Alimentar & Definição; Exemplo; Exercícios do livro didático \\
\hline \multirow{2}{*}{ Maio } & $06 \mid 14$ & Relação Ecológica & Definição; Exercício (descrever) \\
\cline { 2 - 4 } & $15 \mid 18$ & Ar & Definição; Exercício do livro didático (responder, desenho) \\
\hline Jun. & $18|19| 22$ & Componentes do Ar & Definição; Exercício (responder, esquema) \\
\hline Jul. & 08 & Componentes do Ar & Exercícios (responder) \\
\hline \multirow{2}{*}{ Ago. } & 10 & Ar e Saúde & Definição; Exercício (responder, citar) \\
\cline { 2 - 4 } & 31 & Litosfera & Definição \\
\hline Set. & 28 & Litosfera & Exercícios (responder) \\
\hline \multirow{2}{*}{ Out. } & $21 \mid 27$ & Solo & Definição; Exercícios do livro didático (responder, citar); \\
\hline \multirow{2}{*}{ Nov. } & $07 \mid 19$ & Solo e Saúde & Menção ao contexto local \\
\cline { 2 - 4 } & 26 & Água & Definição; Exercícios (responder, citar e explicar) \\
\hline \multirow{2}{*}{ Dez. } & $01|03| 04$ & Água & Definição \\
\cline { 2 - 4 } & 29 & Sistema Solar & Exercícios do livro didático (responder e citar) \\
\hline
\end{tabular}

Fonte: Elaboração própria (2017).

O terrário ${ }^{3}$ pode ser definido como uma experimentação que "trata da verificação e estudo, através de experiências científicas, dos fenômenos físicos e biológicos" (ALONÇO, 1999,

3 Trata-se de um recipiente aberto ou fechado, em que se cultivam algumas espécies de plantas, simulando o seu ambiente natural. Representa em uma micro escala, o meio ambiente, constituído por solo, água, ar, luz e seres vivos, permitindo observar fenómenos da natureza, como o ciclo da (PATRULHA LEÃO, 2013).

Educação \& Formação, Fortaleza, v. 3, n. 7, p. 66-84, jan./abr. 2018

DOI: http://dx.doi.org/

http://seer.uece.br/redufor 
p. 2). A exploração do terrário pode ocorrer por meio de uma atividade de investigação definida por Azevedo (2004) como aquela em que o aluno pode refletir, discutir, explicar e relatar, concretizando uma investigação científica.

$\mathrm{Na}$ observação e análise da referida experimentação, o estudo dos solos pode ser contemplado fazendo-se relações com o meio, quais sejam: a) manejo de solos (composteira na escola); b) horta escolar; c) depósito de lixo; d) uso de agrotóxicos pelos produtores da região; e) produção de insumos caseiros pelos proprietários rurais; f) medidas de combate a microrganismos nas plantações; e g) visitas às propriedades.

Em relação a utilização de agrotóxicos destaca-se o trabalho intitulado "A temática dos Agrotóxicos no Ensino de Ciências: as compreensões de estudantes da Licenciatura em Educação do Campo", de autoria de Fernandes e Stuani (2013) que investigou as concepções sobre agrotóxicos a partir de estudantes do Curso de Licenciatura em Educação do Campo da Universidade Federal de Santa Catarina (UFSC) e como os mesmos abordariam a temática na Educação Básica. As autoras analisaram uma produção de texto, apontando que a temática agrotóxicos permite ser explorada desde a Educação Básica até o Ensino Superior. No Ensino de Ciências pode-se articular a conteúdos conceituais que dialogam com aspectos sociais, políticos, econômicos, ambientais e éticos, vinculando-se também ao enfoque Ciência, Tecnologia e Sociedade (CTS).

Tal trabalho contribui com as possibilidades de articulação quando discute e apresenta a visão dos licenciandos, que consideram que a temática agrotóxicos é uma possibilidade vantajosa de considerar, no Ensino de Ciências, os conhecimentos prévios dos estudantes por meio dos questionamentos: "Você conhece algum defensivo agrícola? Que ações poderiam ser desenvolvidas para que houvesse a redução do uso de agrotóxicos em sua comunidade?" (FERNANDES; STUANI, 2013, p. 6). As autoras também afirmam que vincular os conteúdos curriculares com problemas locais possibilita formar um sujeito consciente de sua realidade e apto a transformá-la.

Outra possibilidade relacionada ao estudo da Ecologia é a horta. A construção e manutenção da mesma pode envolver toda a comunidade escolar e pode ser explorada como um laboratório, estudando as diferentes relações entre as plantas e o solo, o solo e o ar, o solo e a água, entre outras.

A água que compõe o terrário pode ser articulada com os tipos de água e as condições da mesma na região: De onde provém? É tratada? O que fazem? O sistema de abastecimento de 
água dos estudantes é o mesmo da escola? Por que em algumas propriedades a água é encanada e em outras não? Destaca-se também a importância de abranger o estudo sobre o Rio Santa Maria, visto que se situa no sudoeste gaúcho, abrangendo sete municípios, dos quais Dom Pedrito faz parte, sendo relevante identificar e perceber a constituição do mesmo.

Outra possibilidade refere-se à análise de amostras da água, tanto da escola como das propriedades, bem como a exploração da conta/taxa de água, trabalhando as políticas públicas que envolvem o consumo e o desperdício da mesma. No que se refere ao estudo do ar, destacam-se as diferenças entre o campo e a cidade, que podem estar relacionadas às alergias.

Do mesmo modo, as relações ecológicas podem ser abordadas relacionando alguns casos ao estudo de cadeias alimentares (BRASIL, 1998) com organismos locais, identificando os seres vivos que compõem o bioma Pampa como quero-queros, joões-de-barro, sabiás-do-campo, perdizes, ratões-do-banhado, capivaras, tatus-mulita, veados campeiros, graxains e zorrilhos, entre outros. Torna-se possível realizar saídas de campo para o reconhecimento destes seres vivos, relacionando os mesmos com o ser humano, de acordo com a classificação ecológica. E ainda a observação do processo de fotossíntese em diferentes espécies de plantas do bioma local.

Destaca-se a importância de valorizar e contemplar no currículo o bioma Pampa diante da biodiversidade que caracteriza o mesmo, pois corresponde a uma região do estado do Rio Grande do Sul que ocupa uma área de $176.496 \mathrm{~km}^{2}$ (IBGE, 2004), que compreende 63\% do território estadual e $2,07 \%$ do território brasileiro, composto por vastas serras e planícies, morros rupestres a coxilhas, exibindo um imenso patrimônio cultural com campos nativos, matas ciliares e de encosta, arbustos, banhados e afloramentos rochosos (BRASIL, 2016).

Aponta-se também a necessidade de haver uma bibliografia que contemple o estudo do mesmo, visto que os livros disponibilizados pelo Programa Nacional do Livro Didático (PNLD) não aprofundam os aspectos locais das regiões brasileiras, em especial o bioma Pampa, trazendo, muitas vezes, contextos de outros continentes.

\section{CONTEÚDOS DO 7ํ ANO E A ALIMENTAÇÃO}

De acordo com a Tabela 2, foram trabalhados vinte conteúdos no caderno C7, onde se destacam Célula, Vírus, Reino Monera, Reino Protista, Reino Fungi, Reino Animal. 
Tabela 2 - Conteúdos e estrutura do caderno C7 do ano de 2015

\begin{tabular}{|c|c|c|c|}
\hline Mês & Dia & Conteúdo & Características \\
\hline \multirow{4}{*}{ Mar. } & 3 & $\begin{array}{l}\text { Características dos seres } \\
\text { vivos }\end{array}$ & Definição \\
\hline & $12 \mid 19$ & Célula & Definição; Exemplos; Exercícios (responder, citar e completar) \\
\hline & & Classificação dos seres vivos & Definição; Exercícios (responder) \\
\hline & & Nomenclatura Binominal & Definição \\
\hline \multirow{2}{*}{ Abr. } & 10 & $\begin{array}{l}\text { Características dos seres } \\
\text { vivos e células }\end{array}$ & Teste (responder, citar, completar e desenho) \\
\hline & $15|16| 17$ & Vírus & $\begin{array}{l}\text { Definição; Exemplo; Exercícios (responder, citar e desenho); } \\
\text { Trabalho de pesquisa }\end{array}$ \\
\hline \multirow{3}{*}{ Maio } & 14 & Aids & Definição; Exemplo; Exercício (responder) \\
\hline & 18 & Reino Monera & Definição; Exemplo \\
\hline & & Bactérias & Definição; Exemplo \\
\hline \multirow{4}{*}{ Jun. } & 15 & Bactérias & Exercícios (responder, citar); Trabalho de pesquisa \\
\hline & 19 & Reino Protista & Definição; Exemplo \\
\hline & 25 & Feofíceas & Definição; Exemplo; Esquema \\
\hline & & Protozoários & Exercícios (responder, citar); Trabalho de pesquisa \\
\hline Jul. & 2 & Reino Fungi & Definição; Exemplo; Exercício (responder) \\
\hline \multirow{7}{*}{ Ago. } & \multirow{2}{*}{3} & Reino Animal & Definição \\
\hline & & Invertebrados & Definição; Exemplo \\
\hline & \multirow{2}{*}{7} & Filo Porífera & Definição; Exemplo; Exercício (responder, citar) \\
\hline & & Cnidários & Definição; Exemplo \\
\hline & \multirow{3}{*}{31} & Cnidários & Exercícios (responder) \\
\hline & & Estudo dos vermes & Definição; Exercício (responder e citar) \\
\hline & & Esquistossomo & Definição; Exemplo \\
\hline \multirow{11}{*}{ Set. } & \multirow{11}{*}{28} & Nematelmintos & Definição; Exemplo; Exercícios (responder e relacionar) \\
\hline & & Anelídeos & Definição \\
\hline & & Moluscos & Definição; Exercícios (responder, completar e desenho) \\
\hline & & Estudo dos Artrópodes & Definição; Exercícios (responder, completar e desenho) \\
\hline & & Aracnídeos & Definição; Exemplo; Exercício (responder, completar e relacionar) \\
\hline & & Crustáceos & Definição; Exercícios (responder e citar) \\
\hline & & Miriápodes & Definição; Exercícios (responder) \\
\hline & & Atividade Multidisciplinar & Atividades de responder sobre um filme \\
\hline & & Equinodermos & Definição \\
\hline & & Animais vertebrados & Definição; Exercícios (responder, completar e marcar) \\
\hline & & Reino Vegetal & Definição \\
\hline
\end{tabular}

Fonte: Elaboração própria (2017).

Em relação aos conteúdos do 7ำ ano relacionados à Botânica e à Zoologia, muitos são em nível microscópico, tais como vírus e bactérias. Em sua maioria estes conceitos são abordados de maneira reducionista, ilustrados com figuras de livros didáticos ou representações esquemáticas construídas pelo professor - o que não favorece o entendimento da real dimensão desses organismos. 
Para o trabalho com este ano sugere-se uma proposta, segundo os documentos oficiais, a partir da temática "Alimentação", contemplando o eixo "Ser Humano e Saúde". O tema sobre a promoção de práticas alimentares incorporou-se aos documentos oficiais no final dos anos 1990 (BERNARDON, 2011), demonstrando uma proposta sólida de trabalho no Ensino de Ciências. Na Figura 2 demonstra-se uma proposta.

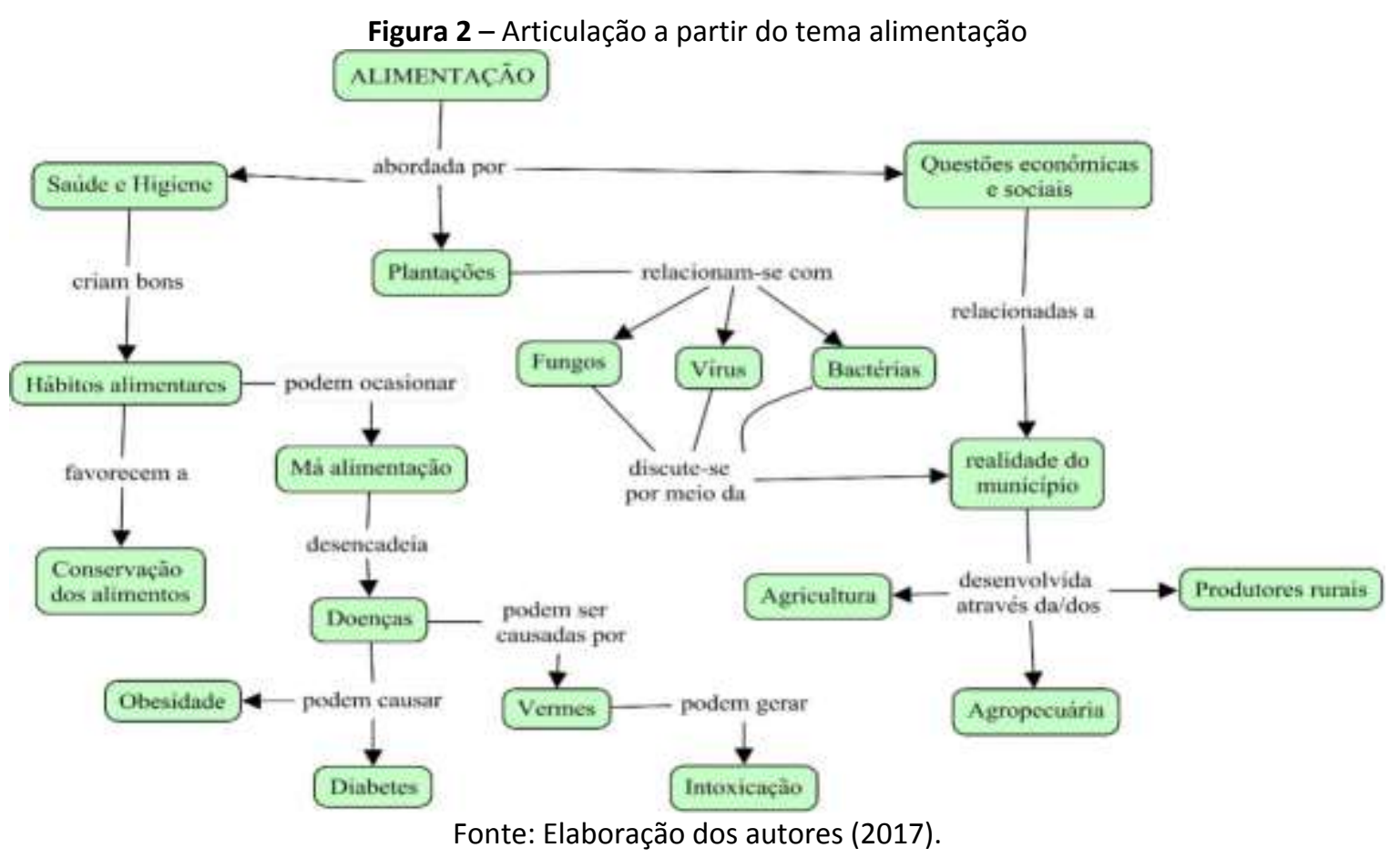

Em saúde e higiene relacionam-se aspectos ambientais, orgânicos e culturais. Na conservação dos alimentos aborda-se o estudo sobre preparo e condições dos alimentos, explora-se também a produção caseira de insumos da região como leite, pão e conservas. Discutem-se igualmente as medidas de prevenção e higiene no preparo e ingestão dos alimentos.

No item má alimentação abordam-se as questões relacionadas a doenças como obesidade, bem como aquelas causadas por vermes e pequenos invertebrados possíveis de serem ingeridos por carnes mal higienizadas, como é o caso da carne de porco. Os vermes do porco, podem causar cisticercose (infeç̧ão intestinal ocasionada pelo verme adulto da Taenia solium). A larva forma uma bolsa cheia de líquido (cisticerco). Quando alguém ingere a carne contaminada, este se expande no intestino, formando uma nova tênia (AMABIS; MARTHO, 2013). Alguns organismos como o Schistosoma mansoni, causador da esquistossomose, habitam açudes, 
barragens, locais úmidos ou vegetações vastas encontradas na região e podem causar complicações no organismo humano pelo contato com a água contaminada.

No item plantação, os conteúdos de vírus, fungos e bactérias podem ser abordados relacionando com a produção de insumos (arroz, milho e soja), bem como horta caseira (alface, tomate, couve e batata). Estudam-se os vírus que podem afetar as plantas, provocando diminuição de crescimento e/ou viroses como leprose (atinge frutas cítricas) e baixeiro (atinge tomateiros e pés de pimentão).

Os fungos podem ser vistos através de algumas doenças como a pinta-preta (Alternaria solani), que afeta a parte aérea da planta causando manchas grandes e escuras ou a septoriose (Septoria lycopersici), que causa pequenas manchas esbranquiçadas afetando primeiramente as folhas mais velhas, mas não os frutos. As bactérias podem ser relacionadas às doenças que atacam o cultivo de alguns insumos, como a mancha bacteriana; causam lesões nos frutos e queda das folhas, favorecida pelas altas temperaturas e umidade. Pode-se aprofundar os estudos e discussões sobre o desenvolvimento de bactérias para potencializar os nutrientes nas plantas.

Em relação às doenças causadas por vírus, fungos, bactérias ou vermes, o trabalho pode ser aprofundado através de atividades de pesquisa com a própria comunidade, levantando relatos das possíveis doenças contraídas na região e com isso divulgando-se medidas de prevenção, de combate ao contágio de tais doenças.

Já em questões econômicas e sociais, discute-se a atividade que mobiliza financeiramente o município, a agricultura e a agropecuária, percebendo e analisando de que forma a produção de arroz e soja, além da pecuária (ovinocultura e bovinocultura), influenciam na geração de renda das famílias e do município. Pode-se abordar também a produção dos pequenos produtores rurais e a questão da comercialização de produtos orgânicos e formação de cooperativas.

O estudo do Reino Plantae e Annimalia pode ser contemplado por meio de conceitos referentes a plantas nativas da região, estabelecendo relação com animais nativos, realizando visitas a propriedades próximas. Também pode-se vincular a construção de hortas, composteiras e ervas medicinais, cultivando a cultura popular do campo. As hortas caracterizam-se como um “instrumento pedagógico capaz de integrar aprendizagens significativas e o cotidiano dos educandos" (BRASIL, 2010, p. 81). Quando inseridas no ambiente escolar, possibilitam desenvolver várias atividades relacionadas aos princípios da Educação Ambiental e Alimentar (FIOROTTI et al., 
2010). O projeto de horta escolar representa uma temática possível para a abordagem do contexto local, escola e seu entorno, contribuindo para a formação integral dos estudantes, pois conhecem aspectos históricos da comunidade, bem como aprendem a planejar o plantio, selecionar plantas e mudas e desenvolver regras de cuidado e colheita (FIOROTTI et al., 2010).

\section{CONSIDERAÇÕES FINAIS}

Considera-se que as alternativas expostas neste trabalho são plausíveis, porém requerem uma proposta de reorganização curricular voltada para a Educação do Campo, caracterizando um novo modelo de Ensino e de Ensino de Ciências. Neste sentido, reforça-se a importância da elaboração de um material que contemple a realidade a ser trabalhada, como os livros didáticos que considerem cada contexto. Estes aspectos tornam-se relevantes, pois valorizam os interesses dos estudantes, da comunidade e também dos professores na efetivação de uma escola comprometida com a emancipação humana.

A partir desta valorização cultural, os sujeitos têm o direito de definir sua própria trajetória enquanto sujeitos pertencentes ao campo, configurando uma ação emancipatória. Portanto, considera-se que pensar uma Educação do Campo na perspectiva do Ensino de Ciências pressupõe rediscutir a realidade vivenciada, contextualizando para além de trazer o contexto como ilustração, mas colocando-o como objeto da aprendizagem.

Tendo em vista as duas dimensões mencionadas é relevante levantar discussões referentes à efetivação do Ensino de Ciências no âmbito de uma escola do campo, perpassando as vivências dos sujeitos, aspectos da realidade da comunidade e conceitos científicos, favorecendo um ensino significativo, que contempla o local onde se vive.

\section{REFERÊNCIAS}

ALONÇO, A. S. Ensaio, experimentação e pesquisa em mecanização agrícola. In: ALONÇO, A. S. Mecanização agrícola. Caderno Didático. Santa Maria: UFSM/CCR/DER, 1999. p. 21-28.

AMABIS, J. M.; MARTHO, G. R. Biologia em contexto. São Paulo: Moderna, 2013.

Educação \& Formação, Fortaleza, v. 3, n. 7, p. 66-84, jan./abr. 2018

DOI: http://dx.doi.org/

http://seer.uece.br/redufor 
AZEVEDO, M. C. P. S. Ensino por investigação: problematizando as atividades em sala de aula. In: CARVALHO, A. M. P. (Org.). Ensino de ciências: unindo a pesquisa e a prática. São Paulo: Thompson, 2004. p. 19-33.

BARDIN, L. Análise de conteúdo. Lisboa: 70, 2009.

BERNARDON, R. Horta escolar no Distrito Federal: instrumento de promoção da alimentação saudável? 2011. 87 f. Dissertação (Mestrado em Nutrição Humana) - Programa de Pós-Graduação em Nutrição, Universidade de Brasília, Brasília, DF, 2011.

BRASIL. Lei no 9.394, de 20 de dezembro de 1996. Estabelece as Diretrizes e Bases da Educação Nacional. Diário Oficial [da] República Federativa do Brasil, Poder Executivo, Brasília, DF, 21 dez. 1996.

BRASIL. Ministério da Educação. Conselho Nacional de Educação. Resolução CNE/CEB no 1, de 3 de abril de 2002. Institui as Diretrizes Operacionais para a Educação Básica nas Escolas do Campo. Diário Oficial [da] República Federativa do Brasil, Poder Executivo, Brasília, DF, 9 abr. 2002.

BRASIL. Ministério da Educação. Fundo Nacional de Desenvolvimento da Educação. Programa Nacional de Alimentação Escolar. Organização das Nações Unidas para a Agricultura e Alimentação. Mapeamento do processo: implantação e implementação do Projeto Educando com a Horta Escolar. Brasília, DF: MEC/FNDE/PNAE/FAO, 2010.

BRASIL. Secretaria de Educação Fundamental. Parâmetros Curriculares Nacionais: Ciências Naturais. Brasília, DF: MEC/SEF, 1998.

BRASIL. Ministério do Meio Ambiente. Pampa 2016. Disponível em: <http://www.mma.gov.br/ biomas/pampa>. Acesso em: 21 fev. 2017.

CARVALHO, A. M. P. Ensino e aprendizagem de Ciências: referenciais teóricos e dados empíricos das sequências de ensino investigativas - (SEI). In: LONGHINI, M. D. (Org.). O uno e o diverso na educação. Uberlândia: UFU, 2011. p. 253-266.

CHASSOT, A. Alfabetização científica: questões e desafios para a educação. 5. ed. ljuí: Unijuí, 2011.

ENISWELER, K. C.; KLIEMANN, C. R. M.; STRIEDER, D. M. O ensino de Ciências na educação do campo: uma pesquisa em dissertações e teses. In: SEMINÁRIO NACIONAL INTERDISCIPLINAR EM EXPERIÊNCIAS EDUCATIVAS. 5., 2015, Paraná. Anais... Paraná: Unioeste, 2015. p. 763-774.

FERNANDES, B. M. Os campos da pesquisa em educação do campo: espaço e território como categorias essenciais. In: MOLINA, M. C. (Org.). Educação do campo e pesquisa: questões para reflexão. Brasília, DF: Ministério do Desenvolvimento Agrário, 2006. p. 27-39.

Educação \& Formação, Fortaleza, v. 3, n. 7, p. 66-84, jan./abr. 2018

DOI: http://dx.doi.org/

http://seer.uece.br/redufor 
FERNANDES, B. M. Territórios da educação do campo. In: ANTUNES-ROCHA, M. I. (Org.). Territórios educativos na educação do campo: escola, comunidade e movimentos sociais. Belo Horizonte: Autêntica, 2012. p. 15-20.

FERNANDES, B. M.; CERIOLI, P. R.; CALDART, R. S. Primeira Conferência Nacional "Por Uma Educação Básica do Campo": texto preparatório. In: ARROYO, M. G.; CALDART, R. S.; MOLINA, M. C. (Org.). Por uma educação do campo. 5. ed. Petrópolis: Vozes, 2011. p. 19-63.

FERNANDES, C. S.; STUANI, G. M. A temática dos Agrotóxicos no ensino de ciências: as compreensões de estudantes da licenciatura em Educação do Campo. In: ENCONTRO NACIONAL DE PESQUISA EM EDUCAÇÃO EM CIÊNCIAS. 9., 2013, Águas de Lindoia. Atas... Águas de Lindoia: UFRJ, 2013. p. 1-8.

FIOROTTI, J. L. et al. Horta: a importância no desenvolvimento escolar. In: ENCONTRO LATINO-AMERICANO DE INICIAÇÃO CIENTÍFICA. 14, 2010, Paraíba. Anais... Paraíba: Univap, 2010. p. 1-7.

FONSECA, E. M.; BIERHALZ, C. D. K. Discutindo articulações entre ensino de Ciências e Educação do Campo através da análise dos cadernos. Revista Brasileira de Educação do Campo, Tocantinópolis, v. 1, n. 2, p. 255-278, 2016.

FONSECA, J. J. S. Metodologia da pesquisa científica. Fortaleza: UEC, Apostila, 2002.

KOLLING, E. J.; CERIOLI, P. R.; CALDART, R. S. (Org.). Educação do campo: identidade e políticas públicas. Brasília, DF: Articulação Nacional por uma Educação do Campo, 2002.

LUCAS, R. E. A. Educação formal/rural permeando as relações do campo: um estudo de caso na Escola Estadual de Tempo Integral de Ensino Fundamental Cândida Silveira Haubman - Arroio Grande, RS. 2008. 357. Tese (Doutorado em Agronomia) - Programa de Pós-Graduação em Agronomia, Universidade Federal de Pelotas, Pelotas, 2008.

MEDEIROS, R. M. V.; ROBL, D. M. Educação rural, saberes e desenvolvimento local. In: MEDEIROS, R. M. V.; FALCADE, I (Org.). Expressões da re-territorialização do campo brasileiro. Porto Alegre: Imprensa Livre, 2013. p. 171-193.

MOLINA, M. C. Educação do campo e pesquisa: questões para reflexão. In: MOLINA, M. C. (Org.). Educação do Campo e Pesquisa: questões para reflexão. Brasília, DF: Ministério do Desenvolvimento Agrário, 2006. p. 7-15.

MOREIRA, M. A. Metodologias de pesquisa em ensino. São Paulo: Livraria da Física, 2011.

NASCIMENTO, F.; FERNANDES, H. L.; MENDONÇA, V. M. O ensino de ciências no Brasil: história, formação de professores e desafios atuais. Revista Histedbr, Campinas, n. 39, p. 225-249, 2010.

OLIVEIRA, D. T. O papel da escola família agrícola de Santa Cruz do Sul na permanência do jovem no campo. 2013. 56 f. Trabalho de Conclusão de Curso (Graduação em Ciências Econômicas) -

Educação \& Formação, Fortaleza, v. 3, n. 7, p. 66-84, jan./abr. 2018

DOI: http://dx.doi.org/

http://seer.uece.br/redufor 
Programa de Graduação em Ciências Econômicas, Universidade Federal do Rio Grande do Sul, Porto Alegre, 2013.

PATRULHA LEÃO. Terrário. 2013. Disponível em: <http://www.pitangui.uepg.br/proad/escoteiros/ index.php/84-destaque/168-terrario>. Acesso em: 21 fev. 2017.

PRIEBBERNOW, H. M. Perspectivas da juventude rural: um estudo a partir da Escola Municipal de Ensino Fundamental Heitor Soares Ribeiro - Canguçu/RS. 2015. 95 f. Trabalho de Conclusão de Curso (Graduação em Geografia) - Programa de Graduação em Geografia, Universidade Federal de Pelotas, Pelotas, 2015.

SANTOS, V. M. O nascimento dos cadernos escolares: um dispositivo de muitas faces. 2002. Dissertação (Mestrado em Educação e Cultura) - Programa de Pós-Graduação em Educação e Cultura, Universidade do Estado de Santa Catarina, Florianópolis, 2002.

SILVA, A. P.; MENEZES, A. C. S.; REIS, E. S. Educação para a convivência com o Semiárido: desafios e possibilidades de um novo fazer. In: ANTUNES-ROCHA, M. I. et al. (Org.). Territórios educativos na educação do campo: escola, comunidade e movimentos sociais. Belo Horizonte: Autêntica, 2012. p. 57-70.

SIQUEIRA, L. S.; ARAÚJO-JORGE, T. C. Práticas docentes e discentes em cadernos de ciências: desenvolvimento metodológico para percepção dos diferentes registros do cotidiano escolar. Revista Brasileira de Estudos Pedagógicos, Brasília, DF, v. 89, n. 221, p. 47-71, 2008.

Recebido em 24 de fevereiro de 2017.

Aceito em 16 de maio de 2017. 